\title{
DNA aptamers that target human glioblastoma multiforme cells overexpressing epidermal growth factor receptor variant III in vitro
}

\author{
Yan TAN ${ }^{1, \#}$, Yu-sheng SHI ${ }^{2, \#}$, Xi-dong WU ${ }^{1}$, Hui-yu LIANG ${ }^{1}$, Yu-bo GAO ${ }^{3}$, Shu-ji LI ${ }^{1}$, Xing-mei ZHANG ${ }^{1, *}$, Fang WANG ${ }^{1}$, \\ Tian-ming $\mathrm{GAO}^{1}$ \\ ${ }^{1}$ Department of Neurobiology, School of Basic Medical Sciences, Southern Medical University, Guangzhou 510515, China; ${ }^{2}$ Department \\ of Radiation Oncology, Nanfang Hospital, Southern Medical University, Guangzhou 510515, China; ${ }^{3}$ First Clinical Medicine College, \\ Southern Medical University, Guangzhou 510515, China
}

\begin{abstract}
Aim: Aptamers are oligonucleic acid or peptide molecules that bind to a specific target molecule in cells, thus may act as effective vehicles for drug or siRNA delivery. In this study we investigated the DNA aptamers that target human glioblastoma multiforme (GBM) cells overexpressing epidermal growth factor receptor variant III (EGFRvIII), which was linked to radiation and chemotherapeutic resistance of this most aggressive brain tumor.

Methods: A 73-mer ssDNA library containing molecules with $30 \mathrm{nt}$ of random sequence flanked by two primer hybridization sites was chosen as the initial library. Cell systematic evolution of ligands by exponential enrichment (Cell-SELEX) method was used to select the DNA aptamers that target EGFRvIII. The binding affinity of the aptamers was measured using a cell-based biotin-avidin ELISA.

Results: After 14 rounds of selection, four DNA aptamers (32, 41, 43, and 47) that specifically bound to the EGFRvIII-overexpressing human glioma U87 $\Delta$ cells with $K_{d}$ values of less than $100 \mathrm{nmol} / \mathrm{L}$ were discovered. These aptamers were able to distinguish the U87 $\Delta$ cells from the negative control human glioma U87MG cells and HEK293 cells. Aptamer 32 specifically bound to the EGFRvIll protein with an affinity similar to the EGFR antibody $\left(K_{d}\right.$ values of aptamer 32 and the EGFR antibody were $0.62 \pm 0.04$ and $0.32 \pm 0.01 \mathrm{nmol} / \mathrm{L}$, respectively), and this aptamer was localized in the cell nucleus.

Conclusion: The DNA aptamers are promising molecular probes for the diagnosis and treatment of GBM.
\end{abstract}

Keywords: DNA aptamer; drug delivery; brain tumor; glioblastoma multiforme; epidermal growth factor receptor variant III; cell systematic evolution of ligands by exponential enrichment

Acta Pharmacologica Sinica (2013) 34: 1491-1498; doi: 10.1038/aps.2013.137

\section{Introduction}

Glioblastoma multiforme (GBM) is the most aggressive form of brain tumor in adults, and its median survival time is less than 12 months $^{[1]}$. The intrinsic ability of GBM tumor cells to invade normal brain tissue prevents complete surgical eradication and results in early local recurrence and mortality in GBM patients. Epidermal growth factor receptor (EGFR) is the first cell-surface tyrosine kinase receptor that has been shown to be amplified and mutated in GBM. The most common form of EGFR mutation is variant III (EGFRvIII), which has an inframe deletion of $801 \mathrm{bp}$. EGFRvIII has also been detected in

\footnotetext{
\# These authors contributed equally to this work.

* To whom correspondence should be addressed.

E-mail zxmray@hotmail.com

Received 2013-05-13 Accepted 2013-08-29
}

other cancers, such as lung cancer, but has not been detected in the corresponding nonmalignant tissues ${ }^{[2-4]}$. EGFR amplification is often accompanied by the up-regulation of EGFRvIII expression, which is associated with poor overall survival in GBM patients ${ }^{[5]}$. Additionally, the expression of EGFRvIII promotes GBM cell motility in vitro ${ }^{[6]}$. Immunohistochemical and reverse transcription polymerase chain reaction (RTPCR) analyses have demonstrated that increased expression of the constitutively active EGFRvIII occurs in 30\%-60\% of GBM patients, while no expression of this mutant is observed in the normal adult brain or any other normal tissues ${ }^{[7,8]}$. Therefore, EGFRvIII is a good therapeutic target for the treatment of GBM.

Antibodies that specifically recognize EGFR and induce rapid apoptosis have been designed and can efficiently kill tumor cells when coupled to cytotoxic reagents ${ }^{[9,10]}$. How- 
ever, these antibodies can also lead to many unpleasant and unavoidable side effects. Given the limitations of antibody techniques, DNA aptamers may be a good alternative therapy. Aptamers selected by adherent cell systematic evolution of ligands by exponential enrichment (Cell-SELEX) exhibit very high selectivity for their targets ${ }^{[11-13]}$. Liu and colleagues ${ }^{[14]}$ reported that aptamers can directly target the biogenesis and maturation of proteins, suggesting that aptamers may be potent inhibitors of stable proteins. Graham and Zarbl ${ }^{[15]}$ validated the ability of aptamers to preferentially recognize highly tumorigenic cancer cell lines from non-tumorigenic cancer cell line revertants. A nuclease resistant RNA-aptamer that specifically binds EGFR has also been reported, and when this aptamer is applied to EGFR-expressing cancer cells, it inhibits EGFR-mediated signaling pathways, resulting in selective cell death ${ }^{[13]}$. The ability of aptamers to distinguish small differences in cell-surface antigens indicates the great potential of using the Cell-SELEX approach for the selection of new biomarkers to identify and isolate subpopulations of various cancer stem cells. In addition to specific target recognition ${ }^{[16,17]}$, aptamers can be designed to target a desired region or in a sequential manner to refine their functions ${ }^{[18,19]}$. They also possess several advantages over naturally occurring antibodies ${ }^{[20]}$, including the ease of synthesis, their stability under standard conditions, a lack of immunogenicity, rapid tissue penetration, and the ease of immobilization and modification on chemical devices.

In this study, we selected aptamers from live cell lines overexpressing a target receptor. DNA aptamers targeting the U87 $\Delta$ cell line, which expresses EGFRvIII, were further investigated to determine whether these anti-EGFRvIII aptamers could specifically recognize and bind to EGFRvIII on the surface of U87 $\Delta$ cells. A biotin-avidin enzyme-linked immunosorbent assay (BA-ELISA) method was used to measure the binding affinity of the aptamers.

\section{Materials and methods Cell culture}

Human glioma U87MG, U87A, and HEK293 cell lines were cultured in Dulbecco's modified Eagle's medium (DMEM) supplemented with $10 \%$ fetal bovine serum (FBS) and were grown in a $95 \%$ air, $5 \% \mathrm{CO}_{2}$ incubator at $37^{\circ} \mathrm{C}$. The U87 $\Delta$ cell line was obtained from Dr Webster CAVENEE (Ludwig Cancer Institute, San Diego, CA, USA), and this cell line has been previously described ${ }^{[2]]}$.

\section{Random library and primers}

The synthetic ssDNA library consisted of random $30 \mathrm{nt}$ sequences flanked by the following primer hybridization sites $^{[22]}$ : 5'-GCAATGGTACGGTACTTCC-(N30)-CAAAAGTGCACGCTACTTTGCTAA-3'.

Double-stranded DNA (dsDNA) was synthesized using the sense and antisense strand primers P1 (5'-GCAATGGTACGGTACTTCC-3') and P2 (5'-TTAGCAAAGTAGCGTGCACTTTTG-3'), respectively. The ssDNA was synthesized by using the sense strand primer (P1 5'-GCAATGGTACG-
GTACTTCC $-3^{\prime}$ ) and the structured $3^{\prime}$ antisense strand primer (P3 5'-GCTAAGCGGGTGGGACTTCCTAGTCCCACCCGCTTAGCAAAGTAGCGTGCACTTTTG-3'). All sequences, including the fluorescein isothiocyanate- (FITC-) and biotinlabeled ssDNA, were synthesized by Invitrogen (Carlsbad, CA, USA).

\section{Cell-SELEX procedures}

The subtractive SELEX strategy was performed as previously described ${ }^{[23]}$, with a few modifications (Table 1). From the fourth round of selection, ssDNA that did not bind to the U87MG cells were incubated with the U87 $\Delta$ cells. Prior to each round, ssDNA was denatured by incubation at $95^{\circ} \mathrm{C}$ for $5 \mathrm{~min}$, then rapidly cooled on ice for $10 \mathrm{~min}$. The denatured ssDNA library ( $2500 \mathrm{pmol}$ for the initial round) was incubated with $2 \times 10^{6}$ adherent cells at $37^{\circ} \mathrm{C}$ for $1 \mathrm{~h}$ in binding buffer $(0.1$ $\mathrm{mg} / \mathrm{mL}$ salmon sperm DNA, $5 \mathrm{mmol} / \mathrm{L} \mathrm{MgCl}_{2}, 0.45 \%$ glucose, and $1 \%$ bovine serum albumin [BSA] in phosphate-buffered saline [PBS]). Unbound ssDNA was washed away with washing buffer ( $5 \mathrm{mmol} / \mathrm{L} \mathrm{MgCl}_{2}$ and $0.45 \%$ glucose in PBS), and the bound ssDNA was scraped and incubated at $95^{\circ} \mathrm{C}$ for 15 min; the supernatant was then obtained by centrifugation at $8000 \times g$ for $10 \mathrm{~min}$.

Table 1. The screening conditions about cell-SELEX.

\begin{tabular}{cccccc}
\hline Cycle & $\begin{array}{c}\text { Cell } \\
\text { density }\end{array}$ & $\begin{array}{c}\text { ssDNA pool } \\
(\mathrm{pmol})\end{array}$ & $\begin{array}{c}\text { Salmon sperm } \\
\text { DNA }(\mu \mathrm{g} / \mu \mathrm{L})\end{array}$ & $\begin{array}{c}\text { Incubate } \\
\text { time }(\mathrm{min})\end{array}$ & $\begin{array}{c}\text { Washing } \\
\text { times }\end{array}$ \\
\hline 1 & $2 \times 10^{6}$ & 3000 & 0.05 & 60 & $1 \mathrm{~min} \times 3$ \\
2 & $1 \times 10^{6}$ & 800 & 0.1 & 40 & $2 \mathrm{~min} \times 3$ \\
3 & $4 \times 10^{5}$ & 200 & 0.1 & 40 & $3 \mathrm{~min} \times 3$ \\
4 & $4 \times 10^{5}$ & 150 & 0.1 & 40 & $2 \mathrm{~min} \times 4$ \\
5 & $4 \times 10^{5}$ & 150 & 0.1 & 30 & $2 \mathrm{~min} \times 4$ \\
6 & $4 \times 10^{5}$ & 100 & 1 & 30 & $2 \mathrm{~min} \times 5$ \\
7 & $4 \times 10^{5}$ & 80 & 1 & 30 & $2 \mathrm{~min} \times 5$ \\
8 & $4 \times 10^{5}$ & 100 & 1 & 30 & $2 \mathrm{~min} \times 5$ \\
9 & $4 \times 10^{5}$ & 100 & 1 & 30 & $2 \mathrm{~min} \times 5$ \\
10 & $4 \times 10^{5}$ & 100 & 1 & 30 & $2 \mathrm{~min} \times 5$ \\
11 & $2 \times 10^{5}$ & 100 & 1 & 30 & $2 \mathrm{~min} \times 5$ \\
12 & $2 \times 10^{5}$ & 100 & 1 & 30 & $2 \mathrm{~min} \times 6$ \\
13 & $2 \times 10^{5}$ & 100 & 1 & 30 & $2 \mathrm{~min} \times 6$ \\
14 & $2 \times 10^{5}$ & 100 & 1 & 30 & $2 \mathrm{~min} \times 6$ \\
\hline
\end{tabular}

\section{Preparation of ssDNA}

ssDNA molecules of unequal length were produced by PCR using primers $\mathrm{P} 1$ and $\mathrm{P} 3$. The PCR mixture $(100 \mu \mathrm{L})$ containing $10 \mu \mathrm{L} 10 \times$ PCR buffer, $0.2 \mathrm{mmol} / \mathrm{L}$ dNTPs, $1 \mu \mathrm{mol} / \mathrm{L}$ each primer, $20 \mathrm{nmol} / \mathrm{L}$ template, and $2.5 \mathrm{U}$ Taq DNA polymerase was incubated at $95^{\circ} \mathrm{C}$ for $1 \mathrm{~min}, 37^{\circ} \mathrm{C}$ for $30 \mathrm{~s}$, and $58^{\circ} \mathrm{C}$ for $40 \mathrm{~s}$ for 30 cycles, followed by a final extension at $58^{\circ} \mathrm{C}$ for 5 min. The PCR products of unequal length were analyzed by electrophoresis in a $10 \%$ polyacrylamide- $7 \mathrm{~mol} / \mathrm{L}$ urea gel, and the lower band of interest was purified from the gel for the next round of selection ${ }^{[24]}$. Following the addition of elution 
buffer $[0.5 \mathrm{~mol} / \mathrm{L}$ ammonium acetate, $0.2 \%$ sodium dodecyl sulfate (SDS), $1 \mathrm{~mol} / \mathrm{L}$ EDTA ( $\mathrm{pH} 8.0$ )], ssDNA was recovered from the solution by ethanol precipitation $(3 \mathrm{~mol} / \mathrm{L}$ sodium acetate, $1 \mathrm{~mol} / \mathrm{L} \mathrm{MgCl}_{2}$ in $100 \%$ ethanol) and allowed to settle for $24 \mathrm{~h}$ at $-20^{\circ} \mathrm{C}$. The resulting sample was centrifuged, and the pellet was rinsed twice with $70 \%$ ethanol and allowed to dry.

Observation of the interactions between aptamers and cells by fluorescence microscopy

The cells were cultured in 48-well plates and grown for $24 \mathrm{~h}$. The cells were then rinsed once with PBS and incubated with 5'-FITC-labeled ssDNA from the initial library in binding buffer $\left(0.1 \mathrm{mg} / \mathrm{mL}\right.$ salmon sperm DNA, $5 \mathrm{mmol} / \mathrm{L} \mathrm{MgCl}_{2}, 0.45 \%$ glucose, and $1 \% \mathrm{BSA}-\mathrm{PBS}$ ) at $37^{\circ} \mathrm{C}$ for $40 \mathrm{~min}$ on a shaker at 30-40 r/min. The attached cells were fixed with $4 \%$ paraformaldehyde (PFA) for $15 \mathrm{~min}$, and the fixed cells were then rinsed three times with PBS and incubated with $4^{\prime}, 6$-diamidino-2-phynylindole (DAPI). The cell-bound aptamers were imaged using a fluorescence microscope (Olympus, Japan) with a $40 \times$ objective.

\section{Imaging of cell-aptamer complexes}

The cells were cultured in chamber slides and grown for $24 \mathrm{~h}$. The cells were then rinsed once with PBS and incubated with the $5^{\prime}$-FITC-labeled aptamers in binding buffer at $37^{\circ} \mathrm{C}$ for $40 \mathrm{~min}$ on a shaker at $30-40 \mathrm{r} / \mathrm{min}$. The attached cells were rinsed with PBS, fixed with $4 \%$ PFA, rinsed with PBS, and then incubated with VECTASHIELD mounting medium containing DAPI (Vector Laboratories Inc, Burlingame, CA, USA). The cell-bound aptamers were then imaged using a confocal microscope with a $40 \times$ objective.

\section{Flow cytometry assays}

The 5'-FITC-labeled aptamer candidates were incubated with $5 \times 10^{5}$ cells at $37^{\circ} \mathrm{C}$ for $40 \mathrm{~min}$ on a shaker at $30-40 \mathrm{r} / \mathrm{min}$. The attached cells were washed twice with $500 \mu \mathrm{L}$ washing buffer (0.1 mg/mL sperm DNA, $5 \mathrm{mmol} / \mathrm{L} \mathrm{MgCl}_{2}, 0.45 \%$ glucose, PBS) and resuspended in $300 \mu \mathrm{L}$ binding buffer. The fluorescence intensity was determined by counting 10000 events using a FACScan cytometer (Becton Dickinson, Franklin Lakes, NJ, USA). The experimental data were analyzed with the Flowjo 7.6.1 software (TreeStar Inc, Ashland, USA).

\section{Biotin-avidin enzyme-linked immunosorbent assay (BA-ELISA) for binding affinity analysis}

ssDNAs from each round were labeled with biotin by PCR. The U87 $\Delta$ cells were plated in 96-well plates (Corning, Corning, NY, USA) at a density of $1 \times 10^{4}$ cells per well. The wells were then washed with PBS and fixed with 4\% PFA for 15 min. The cells were washed three times with PBST $(0.01 \%$ Tween 20 in PBS, pH 7.4) and blocked with 3\% BSA in PBST at room temperature for $2 \mathrm{~h}$. After washing, various concentrations of 5'-biotinylated aptamers were denatured at $95^{\circ} \mathrm{C}$ for $10 \mathrm{~min}$, immediately put on ice, and added to the wells of the 96-well plate; the cells were incubated at $37^{\circ} \mathrm{C}$ for $40 \mathrm{~min}$. The bound aptamers were detected using streptavidin-conjugated horseradish peroxidase (Streptavidin-HRP, 1:1000 in PBS; Sigma, St Louis, MO, USA). The color-developing reaction was initiated by the addition of TMB solution and terminated by the addition of $2 \mathrm{~mol} / \mathrm{L} \mathrm{H}_{2} \mathrm{SO}_{4}$. The absorbance of each well was measured at $450 \mathrm{~nm}$ using a VICTORX3 multilabel plate reader (Perkin Elmer, Waltham, MA, USA). The apparent equilibrium dissociation constant $\left(K_{d}\right)$ for each aptamer were determined by nonlinear regression for one-site binding according to the equation: $Y=B_{\max }{ }^{*} X /\left(K_{d}+X\right)$. This analysis was performed using the SigmaPlot 12.0 software. The mean absorbance of the duplicate samples for each aptamer concentration was used to plot the binding curve.

\section{Pull-down assays using streptavidin-magnetic beads}

The U87 $\Delta$ cell lysates were quantified using the bicinchoninic acid assay with $600 \mu \mathrm{g}$ of total protein per sample. Streptavidin-coated magnetic beads (Promega, Madison, WI, USA) were incubated with the 5'-biotinylated aptamers for $1 \mathrm{~h}$. The negative control was incubated without aptamers. After washing, the protein was added to the bead-biotin-aptamer mixture, and the beads were separated from the solution using a magnetic shelf. To eliminate nonspecific protein adsorption, the beads were washed with PBS five times for $5 \mathrm{~min}$ each. After washing, the resulting samples were dissolved in approximately $50 \mu \mathrm{L}$ of $2 \times$ SDS loading buffer and were evaluated by Western blot analysis.

\section{Western blot analysis}

After washing, the resulting samples were dissolved in approximately $50 \mu \mathrm{L}$ of 2XSDS loading buffer and were separated by $8 \%$ SDS-polyacrylamide gel. Separated proteins in the gels were electrophoretically transferred onto polyvinylidene fluoride (PVDF) membrane at $320 \mathrm{~mA}$ for $3 \mathrm{~h}$. Then the PVDF membrane was blocked with $5 \%$ skim milk in TBS containing $0.05 \%$ Tween 20 . After washing the membrane with TBS-T, EGFR antibody diluted in TBS-T containing $0.5 \%$ BSA, was added and incubated for overnight at $4{ }^{\circ} \mathrm{C}$. The bound antibodies were detected by horseradish peroxidaseconjugated anti-rabbit Ig secondary antibody followed by ECL detection system.

\section{Statistical analysis}

Date are reported as mean \pm SEM. The differences among groups were determined by one-way ANOVA using SPSS13.0.

\section{Results}

\section{Aptamer candidates for U87 $\Delta$ cells selected by cell-SELEX}

Cultured U87 $\Delta$ cells were used as the target for the aptamer selection while U87MG cells were used as a negative control (Figure 1). U87MG cells were from the fourth round to reduce the collection of DNA sequences that could bind to common surface molecules present on both cell types. After multiround selection, target-cell-specific aptamer candidates were enriched. The progress of the selection process was monitored using a biotin-avidin based ELISA method (BA-ELISA). 


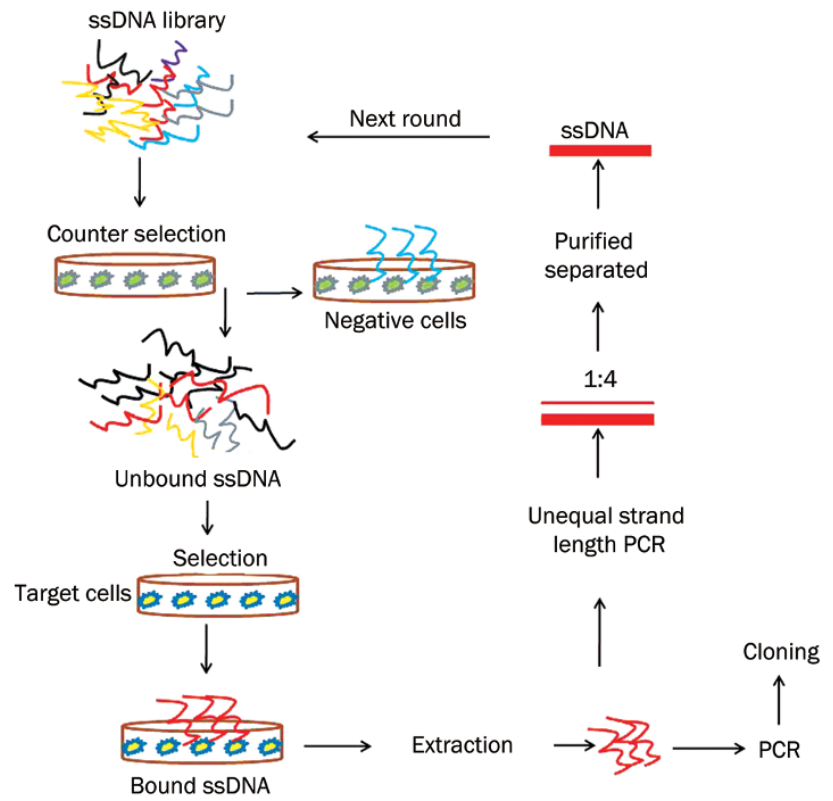

Figure 1. Schematic representation of adherent cell-based aptamer selection. Briefly, the ssDNA pool was incubated with U87MG cells (negative control) for counter selection. Unbound DNA was then incubated with U87 $\Delta$ cells (target cells). After washing, the bound DNAcell complexes were scraped and eluted by heating to $95^{\circ} \mathrm{C}$. Following centrifugation, the supernatant was collected, and the selected DNA was amplified by PCR. PCR products were separated into SSDNA for next-round selection or cloned and sequenced for aptamer identification in last-round selection.

ssDNA from each round were labeled with biotin by PCR and incubated with the U87 $\Delta$ and U87MG cells. Significant increases in the optical density of the U87 $\Delta$ cells indicated that the DNA probes specifically recognized unique surface targets on the U87 $\Delta$ cells, and these aptamers were then selected (Figure 2). However, apparent enrichment of DNA binding to the control cells was also observed; this may be due to the lack of specific adsorption of the U87MG cells. We chose to clone and sequence the 14th round ssDNAs. Of the 18 aptamer candidates, 9 sequences appeared twice. Among these 9 different sequences, 4 were randomly chosen for further studies (underlined in Table 2). Additionally, the base group $\mathrm{T}$ was enriched in the random regions, perhaps because the $\mathrm{T}$ base can maintain the stability of DNA.

\section{Specificity of the aptamers for the U87 $\Delta$ cells}

Binding assays using flow cytometry and BA-ELISA were performed to assess the affinity of the selected sequences for the target cells. FITC-tagged or biotin-labeled DNA sequences were incubated with U87 $\Delta$, U87MG, or HEK293 cells, and the aptamers that specifically bound to the U87 $\triangle$ cells were observed by fluorescence microscopy (Figure 3A). Additionally, confocal imaging was use to observe the cellular localization of the aptamers (Figure 3B). We found that the FITC fluorescence of aptamers 41,43 , and 32 appeared to be localized within the nuclei, whereas aptamers 41 and 43 were also

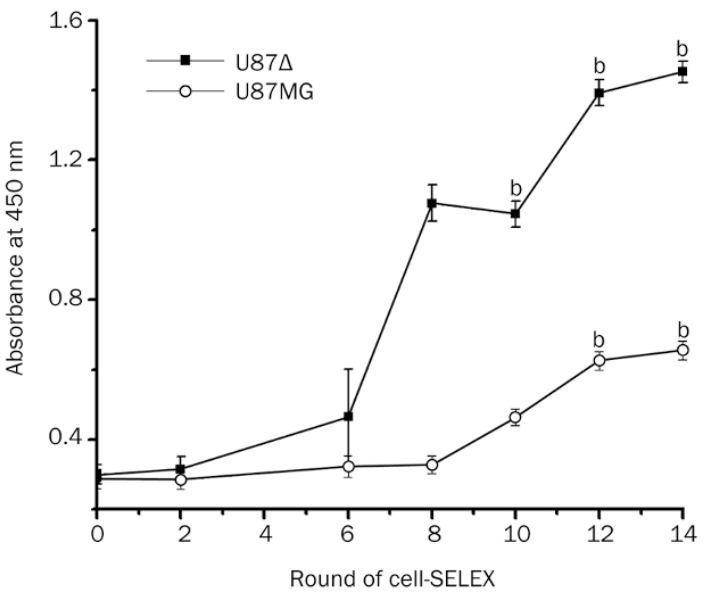

Figure 2. ELISA to monitor the binding of selected pools to U87 $\triangle$ cells and U87MG cells. The optical density was measured at $450 \mathrm{~nm}$ using a VICTORX3 Multilabel plate reader. For U87 $\Delta$ cells, there was an increase in binding capacity of the pool as the selection progressed $(n=3)\left({ }^{b} P<0.05\right.$ vs the primary library), while little change was observed in the control cells. The data was analysed by one-way ANOVA.

Table 2. Sequences of aptamer candidates.

\begin{tabular}{cl}
\hline № & \multicolumn{1}{c}{ Aptamer sequences (random region) } \\
\hline $29 / 76$ & 5'-TCTATCTTTTTTTCGTTGATGTTTTGTTCT-3' \\
$\underline{\underline{32} / 71}$ & 5'-TGAATGTTGTTTTTTCTCTTTTCTATAGTA-3' \\
$\underline{\underline{3} / 88}$ & 5'-GTCATCAGCTTGTGATGTGGATGCGAACTG-3' \\
$\underline{22 / 41}$ & 5'-TTTTGTTGTTTTTTTTCTGTATTTATCGAT-3' \\
\hline 9/10 & 5'-CTACTTATTGTTATTATGATTGGTAGTGTT-3' \\
$37 / 62$ & 5'-TTATTTATTTCTGGAAGTAATGATTGTTTG-3' \\
$40 / 45$ & 5'-ATTTGTCTTCTTATGATTTGTTTGTTCCTT-3' \\
$55 / 58$ & 5'-TTTGTGATTTTTTGGTTGTTATTTTTTTTC-3' \\
$\underline{47 / 13}$ & 5'-TCTATTCAATGTTTAATTTTGTGATTTGTA-3' \\
\hline
\end{tabular}

present in the cytoplasm. The transportation of the aptamers into the cells may have occurred through endocytosis ${ }^{[25,26]}$; therefore, we hypothesized that some of these aptamers may recognize EGFRvIII. Aptamer 47 also localized to the cell surface. Flow cytometry analysis demonstrated that all four aptamers specifically bound to the U87 $\Delta$ cell line (Figure 3C).

The cell-SELEX method generated high-affinity molecular probes for the target cells

BA-ELISA showed that the $K_{d}$ value of the initial library was higher than the other aptamers, meaning that aptamers 41,43 , 47 , and 32 were specific for the U87 $\triangle$ cell line and bound with a high affinity. Aptamer $32\left(K_{\mathrm{d}}=0.62 \pm 0.04 \mathrm{nmol} / \mathrm{L}, R=0.9957\right)$ had an affinity similar to the EGFR antibody $\left(K_{\mathrm{d}}=0.32 \pm 0.01\right.$ $\mathrm{nmol} / \mathrm{L}, R=0.9989)$, which was used as a positive control. The $K_{\mathrm{d}}$ values of all four aptamers were less than $100 \mathrm{nmol} / \mathrm{L}$, proving that the selected aptamers had high binding affinities for the U87 $\Delta$ cells (Figure $4 \mathrm{~A}$ ). 

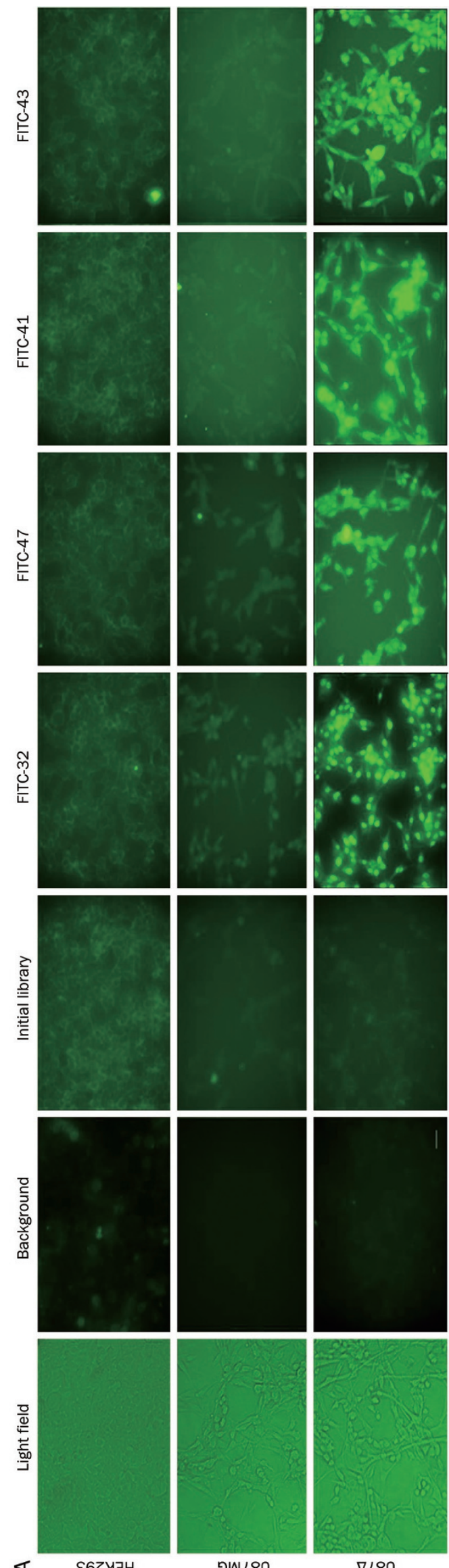

эW $\angle 8 \cap$
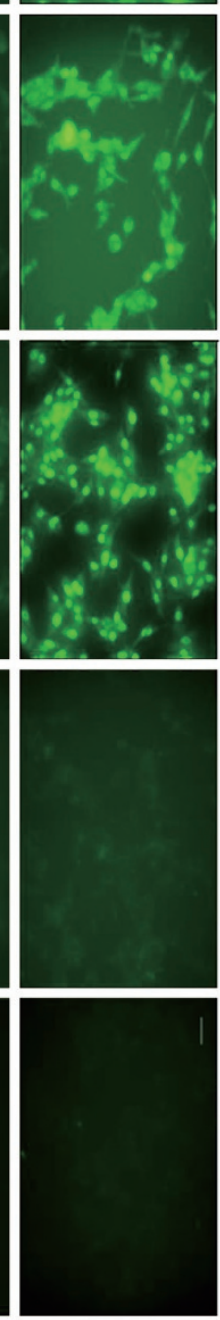

$\nabla<8 \cap$

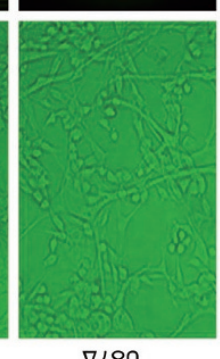

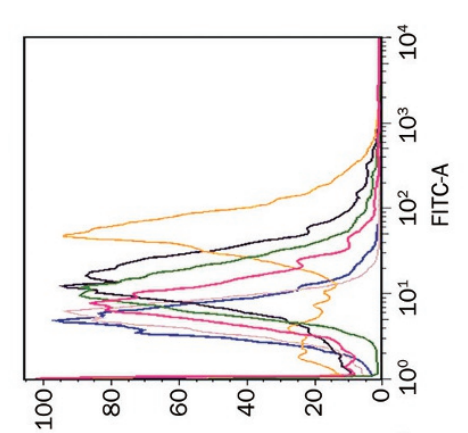
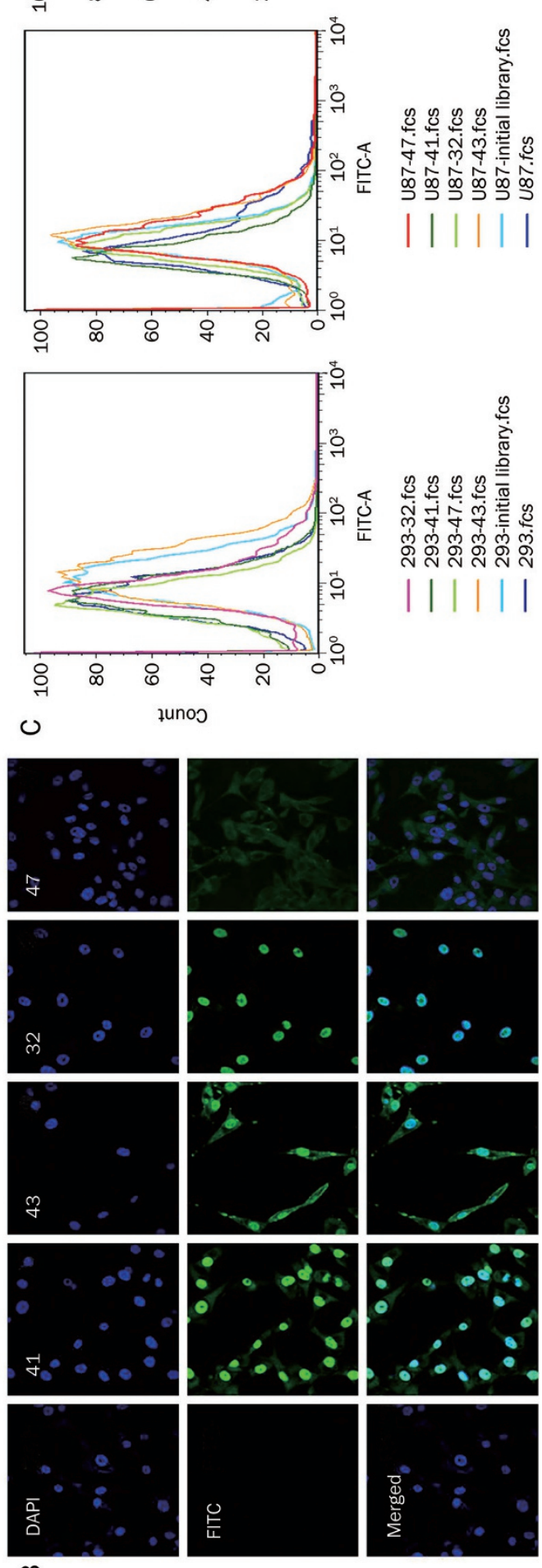

$m$

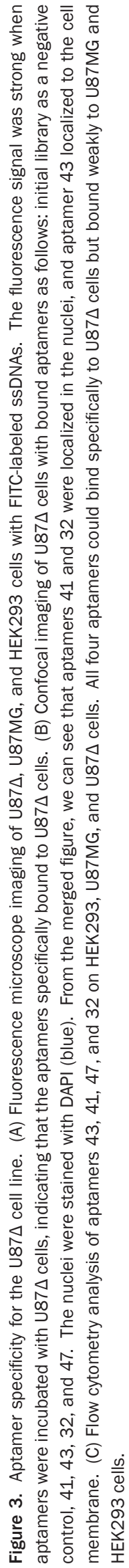



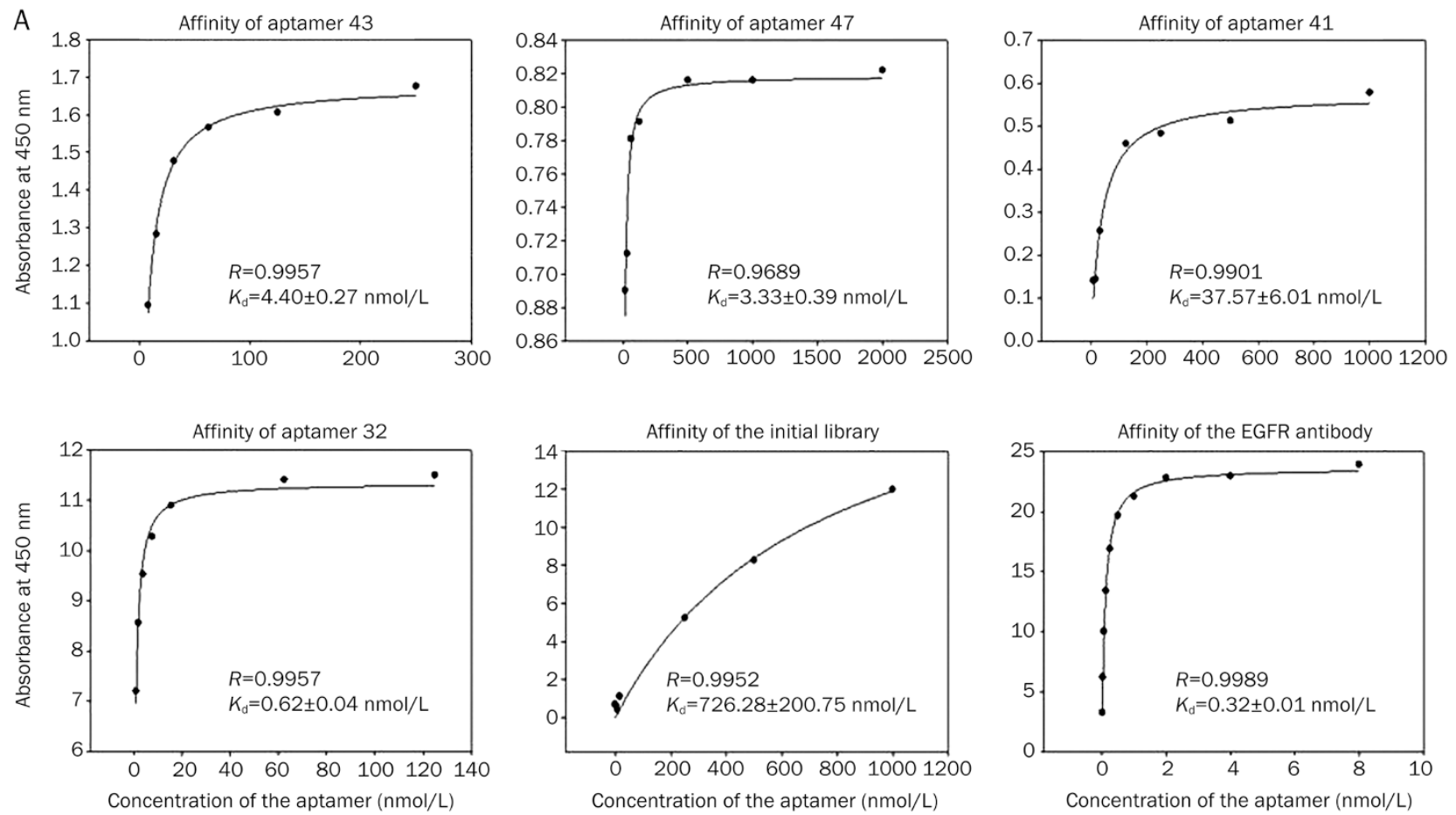

B

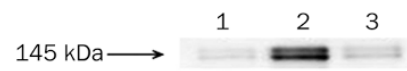

Figure 4. Aptamers had high binding affinities with U87 cells specifically. (A) Binding curves of aptamers 43 , 41, 47, and 32 . The $K_{d}$ values of all four aptamers were less than $100 \mathrm{nmol} / \mathrm{L}$. This result proved that the selected aptamers had high binding affinities for U87 cells. (B) Identification of binding affinity between biotin-aptamer 32 and EGFRvIll protein by Western blot analysis. Lanes (left to right): (1) no aptamer control; (2) biotin-aptamer 32; (3) initial library control. Samples were incubated with streptavidin-magnetic beads respectively, and the complexes were incubated with U87 cell lysates. EGFR antibody was used to detect whether the complex could bind EGFRvIll protein.

\section{Aptamer 32 targeted EGFRvIII}

To determine whether the aptamers targeted the EGFRvIII molecule, pull-down assays were performed using the biotinylated aptamer 32. We observed that EGFRvIII from the U87 $\Delta$ cells was able to interact with aptamer 32. As a control, cell lysates were incubated with the initial library or without aptamers to eliminate the possibility of nonspecific binding of the streptavidin-magnetic beads (Figure 4B).

\section{Discussion}

Recently, many groups have reported that aptamers selected using live cells can be used to identify a specific cell type. However, the number of aptamers that can bind a defined receptor within a complex target can be very small. By using the cell-SELEX method with an appropriate target cell and control cell populations ( $e g$, cells with different protein expression levels or protein conformations), multiple aptamers that recognize a specific membrane protein on the target-positive cells can be selected. We found that DNA aptamer 32 can bind EGFRvIII, which suggests that aptamer 32 could be used as an alternative to an antibody in the detection of EGFRvIII. Because aptamers can bind to specific target proteins with high affinity, they have been referred to as "chemical antibodies"[27]. It is worth noting that DNA aptamers are easily synthesized, while antibody generation relies on animal immune systems. Additionally, aptamers are more stable than antibodies, which makes them useful in disease diagnosis, including cancer ${ }^{[28]}$.

Recently, researchers have developed a series of aptamers through whole-cell SELEX that tightly bind to human glioma cells. Among these aptamers, GBM128 and GBM131 that targeted the cultured human glioblastoma cell line U118-MG were selected by Kang ${ }^{[11]}$. Clinical tissues were also tested, and the results showed that these two aptamers can bind to different clinical glioma tissues but not to normal brain tissues. It has been reported that the GMT-8 aptamer has the highest binding affinity for U87 cells ${ }^{[29]}$. Aptamers that target GBM cells may serve as effective ligands for GBM targeted therapy that may improve drug accumulation and enhance tumor penetration. In this study, we chose the GBM cell lineU87 $\Delta$, which overexpresses EGFRvIII, as a positive target, and aptamers that specifically bound U87 $\Delta$ cells were screened by cell-SELEX. Some aptamers identified U87 $\Delta$ cells by binding the EGFRvIII protein, which is overexpressed on the cell membrane.

Aptamers 41, 43, and 32 were found to localize in the nuclei. However, the localization mechanism by which these aptamers localize to the nuclei remains unclear. It is possible that these aptamers could be used as carriers to deliver chemical 
drugs or siRNAs to the target cells ${ }^{[30,31]}$. Chu and colleagues ${ }^{[32]}$ performed an experiment in which the anti-prostate-specific membrane antigen aptamer A9, which binds to prostate tumor cells, was coupled to siRNA via a modular streptavidin bridge, and they showed that the attached siRNA molecule could inhibit gene expression. Chu and colleagues demonstrated that aptamers can mediate the delivery of siRNA if these aptamers can be endocytosed by a cell-surface marker receptor. In conclusion, our aptamers may be useful for the treatment of GBM, and we are currently conducting additional studies to investigate this possibility.

\section{Acknowledgements}

This work was supported by grants from the National Natural Science Foundation of China (№ 30973481 and 81272509) and the Guangdong Natural Science Foundation (No 9151051501000053 and 07005145). We would like to thank Shu-hu LIU, Jie WEI, Jing ZHANG, and Ying FANG for their assistance with the experiments. We would also like to thank Professor Tian-ming GAO for providing us with a new experimental platform as well as Ri-yang ZHOU and Charles DEAK for providing assistance with the language.

\section{Author contribution}

Xing-mei ZHANG designed the study. Yan TAN, Yu-sheng SHI, and Xi-dong WU performed the research. Hui-yu LIANG, Fang WANG, Shu-ji LI, and Yu-bo GAO contributed new analytical tools, and Yan TAN and Yu-sheng SHI analyzed the data and wrote the paper. Tian-ming GAO provided hardware support of the experiments.

\section{Abbreviations}

Cell-SELEX, cell systematic evolution of ligands by exponential enrichment; EGFR, epidermal growth factor receptor; EGFRvIII, epidermal growth factor receptor variant III; GBM, glioblastoma multiforme; ELISA, enzyme-linked immunosorbent assay; U87-EGFRvIII cell (U87A), U87 MG cells that overexpresses epidermal growth factor receptor variant III.

\section{References}

1 Maher EA, Furnari FB, Bachoo RM, Rowitch DH, Louis DN, Cavenee WK, et al. Malignant glioma: genetics and biology of a grave matter. Genes Dev 2001; 15: 1311-33.

2 Okamoto I, Kenyon LC, Emlet DR, Mori T, Sasaki J, Hirosako S, et al. Expression of constitutively activated EGFRvIll in non-small cell lung cancer. Cancer Sci 2003; 94: 50-6.

3 Moscatello DK, Holgado-Madruga M, Godwin AK, Ramirez G, Gunn G, Zoltick PW, et al. Frequent expression of a mutant epidermal growth factor receptor in multiple human tumors. Cancer Res 1995; 55: 5536-9.

4 Kuan CT, Wikstrand CJ, Bigner DD. EGF mutant receptor vIII as a molecular target in cancer therapy. Endocr Relat Cancer 2001; 8: 83-96.

5 Furnari FB, Fenton T, Bachoo RM, Mukasa A, Stommel JM, Stegh A, et al. Malignant astrocytic glioma: genetics, biology, and paths to treatment. Genes Dev 2007; 21: 2683-710.

6 Cai XM, Tao BB, Wang LY, Liang YL, Jin JW, Yang Y, et al. Protein phosphatase activity of PTEN inhibited the invasion of glioma cells with epidermal growth factor receptor mutation type III expression. Int J Cancer 2005; 117: 905-12.

7 Pelloski CE, Ballman KV, Furth AF, Zhang L, Lin E, Sulman EP, et al. Epidermal growth factor receptor variant III status defines clinically distinct subtypes of glioblastoma. J Clin Oncol 2007; 25: 2288-94.

8 Yoshimoto K, Dang J, Zhu S, Nathanson D, Huang T, Dumont R, et al. Development of a real-time RT-PCR assay for detecting EGFRvIII in glioblastoma samples. Clin Cancer Res 2008; 14: 488-93.

9 Reist CJ, Archer GE, Kurpad SN, Wikstrand CJ, Vaidyanathan G, Willingham MC, et al. Tumor-specific anti-epidermal growth factor receptor variant III monoclonal antibodies: use of the tyraminecellobiose radioiodination method enhances cellular retention and uptake in tumor xenografts. Cancer Res 1995; 55: 4375-82.

10 Wikstrand CJ, Hale LP, Batra SK, Hill ML, Humphrey PA, Kurpad SN, et al. Monoclonal antibodies against EGFRvIII are tumor specific and react with breast and lung carcinomas and malignant gliomas. Cancer Res 1995; 55: 3140-8.

11 Kang D, Wang J, Zhang W, Song Y, Li X, Zou Y, et al. Selection of DNA aptamers against glioblastoma cells with high affinity and specificity. PloS One 2012; 7: e42731.

12 Ohuchi SP, Ohtsu T, Nakamura Y. Selection of RNA aptamers against recombinant transforming growth factor-beta type III receptor displayed on cell surface. Biochimie 2006; 88: 897-904.

13 Esposito CL, Passaro D, Longobardo I, Condorelli G, Marotta P, Affuso A, et al. A neutralizing RNA aptamer against EGFR causes selective apoptotic cell death. PloS One 2011; 6: e24071.

14 Liu Y, Kuan CT, Mi J, Zhang X, Clary BM, Bigner DD, et al. Aptamers selected against the unglycosylated EGFRvIII ectodomain and delivered intracellularly reduce membrane-bound EGFRvIII and induce apoptosis. Biol Chem 2009; 390: 137-44.

15 Graham JC, Zarbl H. Use of cell-SELEX to generate DNA aptamers as molecular probes of HPV-associated cervical cancer cells. PloS One 2012; 7: e36103.

16 Lau IP, Ngan EK, Loo JF, Suen YK, Ho HP, Kong SK. Aptamer-based bio-barcode assay for the detection of cytochrome-c released from apoptotic cells. Biochem Biophys Res Commun 2010; 395: 560-4.

17 Low SY, Hill JE, Peccia J. A DNA aptamer recognizes the Asp $f$ allergen of Aspergillus fumigatus. Biochem Biophys Res Commun 2009; 386: 544-8.

18 Mallikaratchy P, Stahelin RV, Cao Z, Cho W, Tan W. Selection of DNA ligands for protein kinase C-delta. Chem Commun (Camb) 2006; 14 : 3229-31.

19 Mendonsa SD, Bowser MT. In vitro selection of high-affinity DNA ligands for human IgE using capillary electrophoresis. Anal Chem 2004; 76: 5387-92.

20 Famulok M, Hartig JS, Mayer G. Functional aptamers and aptazymes in biotechnology, diagnostics, and therapy. Chem Rev 2007; 107: 3715-43.

21 Zhan Y, O'Rourke DM. SHP-2-dependent mitogen-activated protein kinase activation regulates EGFRvIII but not wild-type epidermal growth factor receptor phosphorylation and glioblastoma cell survival. Cancer Res 2004; 64: 8292-98.

22 Li S, Xu H, Ding H, Huang Y, Cao X, Yang G, et al. Identification of an aptamer targeting hnRNP A1 by tissue slide-based SELEX. J Pathol 2009; 218: 327-36.

23 Wang $C$, Zhang $M$, Yang $G$, Zhang $D$, Ding $H$, Wang $H$, et al. Singlestranded DNA aptamers that bind differentiated but not parental cells: subtractive systematic evolution of ligands by exponential enrichment. J Biotechnol 2003; 102: 15-22.

24 Cao X, Li S, Chen L, Ding H, Xu H, Huang Y, et al. Combining use of a 
panel of ssDNA aptamers in the detection of Staphylococcus aureus. Nucleic Acids Res 2009; 37: 4621-28.

25 Chen $\mathrm{CH}$, Dellamaggiore KR, Ouellette CP, Sedano CD, Lizadjohry M, Chernis GA, et al. Aptamer-based endocytosis of a lysosomal enzyme. Proc Natl Acad Sci U S A 2008; 105: 15908-13.

26 Bagalkot V, Farokhzad OC, Langer R, Jon S. An aptamer-doxorubicin physical conjugate as a novel targeted drug-delivery platform. Angew Chem Int Ed Engl 2006; 45: 8149-52.

27 Zhou J, Rossi JJ. Bivalent aptamers deliver the punch. Chem Biol 2008; 15: 644-5.

28 Tombelli S, Minunni M, Mascini M. Aptamers-based assays for diagnostics, environmental and food analysis. Biomol Eng 2007; 24:
191-200.

29 Bayrac AT, Sefah K, Parekh P, Bayrac C, Gulbakan B, Oktem HA, et al. In vitro selection of DNA aptamers to glioblastoma. ACS Chem Neurosci 2011; 2: 175-81.

30 McNamara JO 2nd, Andrechek ER, Wang Y, Viles KD, Rempel RE, Gilboa E, et al. Cell type-specific delivery of siRNAs with aptamersiRNA chimeras. Nat Biotechnol 2006; 24: 1005-15.

31 Prow TW, Yu C, Hu Y, Duan J, Yuan W, Wang C, et al. Novel aptamernanoparticle bioconjugates enhances delivery of anticancer drug to MUC1-positive cancer cells in vitro. PloS One 2011; 6: e24077.

32 Chu TC, Twu KY, Ellington AD, Levy M. Aptamer mediated siRNA delivery. Nucleic Acids Res 2006; 34: e73. 